Journal of Mathematics and Informatics

Vol. 11, 2017, 55-61

ISSN: 2349-0632 (P), 2349-0640 (online)

Published 11 December 2017

www.researchmathsci.org

DOI: http://dx.doi.org/10.22457/jmi.v11a8

Journal of

Mathematics and

Informatics

\title{
Integer Solution of the Homogeneous Bi-Quadratic Diophantine Equation with Five Unknowns
}

$$
(x-y)\left(x^{3}-y^{3}\right)=\left(z^{2}-w^{2}\right) p^{2}
$$

\author{
R.Umamaheswari ${ }^{1}$ and A.Kavitha ${ }^{2}$ \\ ${ }^{1}$ Department of Mathematics, Shrimati Indira Gandhi College \\ Trichy-2,Tamilnadu, India. \\ 1e-mail: umadevmsc@gamil.com \\ 2e-mail: kavithabalasubramanian63@yahoo.com \\ Received 10 November 2017; accepted 10 December 2017
}

\begin{abstract}
The homogeneous equation with five unknown $(x-y)\left(x^{3}-y^{3}\right)=\left(z^{2}-w^{2}\right) p^{2}$ is analyzed for its nonzero distinct integer solutions. Employing the transformation and applying the method of factorization, different patterns of nonzero distinct integer solutions to the above bi-quadratic equation are obtained. A few interesting relations between the solutions and special number patterns namely polygonal and pyramidal numbers are presented.
\end{abstract}

Keywords: Homogeneous bi-quadratic, Bi-quadratic equation with five unknown, integer solutions.

\section{AMS Mathematics Subject Classification (2010): 11D25}

\section{Introduction}

Bi-quadratic Diophantine equations, homogeneous and non -homogeneous, have aroused the interest of numerous mathematicians since ambiguity as can be seen from [1-2] particularly In [3-5] bi-quadratic diophantine equations with three unknowns are considered In [6-9] bi-quadratic equation with four unknowns are considered In [10-12] bi-quadratic equation with five unknowns are considered. In this paper, another interesting bi-quadratic equation with five unknown given by

$$
(x-y)\left(x^{3}-y^{3}\right)=\left(z^{2}-w^{2}\right) p^{2}
$$

is considered and five different patterns of integral solutions are illustrated. A few interesting properties between the solutions and special number patterns are exhibited.

\section{Notation}

$$
\begin{array}{ll}
>T_{m, n}=n\left(1+\frac{(n-1)(m-2)}{2}\right) & \text { - Polygonal number of rank } \mathrm{n} \text { with side } \mathrm{m} . \\
>S_{n}=6 n(n-1)+1 & - \text { Star number of rank } \mathrm{n}
\end{array}
$$




\section{R.Umamaheswari and A.Kavitha}

$$
\begin{array}{ll}
>P R_{n}=n(n+1) & \text { - Pronic number of rank n } \\
>C P_{n, 3}=\frac{n^{3}+n}{2} & \text { - Centered triangular pyramidal number of rank n } \\
>C P_{n, 6}=n^{3} & \text {-Centered hexagonal pyramidal number of rank n } \\
>G_{n o_{2}}=2 n-1 & \text { - Gnomonic number } \\
>S O_{n}=n\left(2 n^{2}-1\right) & \text { - Stella Octangular number of rank n } \\
>J_{n}=\frac{1}{3}\left(2^{n}-(-1)^{n}\right) & \text { - Jacobsthal number of rank n. }
\end{array}
$$

\section{Method of analysis}

The Diophantine equation representing the biquadratic equation with five unknowns under consideration is.

$$
(x-y)\left(x^{3}-y^{3}\right)=\left(z^{2}-w^{2}\right) p^{2}
$$

The substitution of the linear transformations in (1) gives

$x=u+v, \mathrm{y}=\mathrm{u}-\mathrm{v}, \mathrm{z}=\mathrm{uv}+1, \mathrm{w}=\mathrm{uv}-1$

$u^{2}+3 v^{2}=p^{2}$

We solve (3) through different methods and thus obtained different patterns of solutions to (1)

\subsection{Pattern 1}

Equation (3) can be written as

$$
\frac{p+u}{3 v}=\frac{v}{p-u}=\frac{A}{B} \quad \text { wher e } \mathrm{B} \neq 0
$$

Equation (4) is equivalent to the system of double equations.

$$
\left.\begin{array}{l}
u A+\mathrm{vB}-\mathrm{pA}=0 \\
u B+\mathrm{vA}-\mathrm{pB}=0
\end{array}\right\}
$$

Solving (5) by applying the method of cross multiplication and using (2) the corresponding non-zero integer solution to (1) are obtained as

$$
\begin{aligned}
& x=x(\mathrm{~A}, \mathrm{~B})=3 \mathrm{~A}^{2}-B^{2}+2 A B \\
& y=y(\mathrm{~A}, \mathrm{~B})=3 \mathrm{~A}^{2}-B^{2}-2 A B \\
& z=z(\mathrm{~A}, \mathrm{~B})=6 \mathrm{~A}^{2} B-2 A B^{2}+1 \\
& w=w(\mathrm{~A}, \mathrm{~B})=6 \mathrm{~A}^{3} B-2 A B^{3}+1 \\
& p=p(\mathrm{~A}, \mathrm{~B})=\mathrm{A}^{2}+3 B^{2}
\end{aligned}
$$

\section{Properties:}

1. $5 x(\mathrm{~A}, 1)+5 y(\mathrm{~A}, 1)+4 p(\mathrm{~A}, 1)=6^{2} A^{2}$ is a perfect square

2. $z(\mathrm{~A}+1, \mathrm{~A})-\mathrm{p}(\mathrm{A}+1, \mathrm{~A})+2 t_{4, A}-20 t_{4, A}+4=0$

3. $p\left(2^{\mathrm{n}}, 1\right)=3 \mathrm{~J}_{2 \mathrm{~A}+4}$ 
Integer Solution of the Homogeneous Bi-Quadratic Diophantine Equation with Five Unknowns

\section{Remark:}

In addition to (4), (3) may also be expressed in the form of ratios as presented below $\frac{3 \mathrm{v}}{p-u}=\frac{\mathrm{p}+\mathrm{u}}{\mathrm{v}}=\frac{\mathrm{A}}{\mathrm{B}} \quad$ where $\mathrm{B} \neq 0$

Following the procedure as presented above the corresponding non zero integer solutions to (1) are found to be as given below.

$$
\begin{aligned}
& x=x(\mathrm{~A}, \mathrm{~B})=3 \mathrm{~B}^{2}-A^{2}-2 A B \\
& y=y(\mathrm{~A}, \mathrm{~B})=3 \mathrm{~B}^{2}-A^{2}+2 A B \\
& z=\mathrm{z}(\mathrm{A}, \mathrm{B})=\mathrm{A}^{4}+9 B^{4}-10 A^{2} B^{2}+1 \\
& w=\mathrm{w}(\mathrm{A}, \mathrm{B})=\mathrm{A}^{4}+9 B^{4}-10 A^{2} B^{2}-1 \\
& p=\mathrm{p}(\mathrm{A}, \mathrm{B})=\mathrm{A}^{2}+3 B^{2}
\end{aligned}
$$

\section{Properties:}

$$
\begin{aligned}
& \text { 1. } p(A, A)-4 t_{4, A}=0 \\
& \text { 2. } x(\mathrm{~A}, \mathrm{~A})+y(\mathrm{~A}, \mathrm{~A})=4 A^{2} \text { is a perfect square } \\
& \text { 3. } x(1, \mathrm{~B})+p(1, \mathrm{~B})-2 \mathrm{PR}_{\mathrm{A}}-4=0
\end{aligned}
$$

\subsection{Pattern 2}

$$
\text { Let } p=\mathrm{p}(\mathrm{a}, \mathrm{b})=a^{2}+3 b^{2}
$$

where $\mathrm{a}$ and $\mathrm{b}$ are non-zero district integers

Using (3) and (7) and applying the method of factorization, define

$$
(u+i \sqrt{3} v)(u-i \sqrt{3} v)=(a+i \sqrt{3} b)^{2}(a-i \sqrt{3} b)^{2}
$$

Equating real and imaginary parts we have

$$
\left.\begin{array}{l}
u=a^{2}-3 b^{2} \\
v=2 a b
\end{array}\right\}
$$

using (8) in (2), the corresponding non-zero distinct integral solutions of (1) are given by

$$
\begin{aligned}
& x=x(\mathrm{a}, \mathrm{b})=a^{2}-3 b^{2}+2 a b \\
& y=y(\mathrm{a}, \mathrm{b})=a^{2}-3 b^{2}-2 a b \\
& z=z(\mathrm{a}, \mathrm{b})=2 a^{3} b-6 a b^{3}+1 \\
& w=w(\mathrm{a}, \mathrm{b})=2 a^{3}-6 a b^{3}-1
\end{aligned}
$$

Thus, (7) and (9) represent the non- zero distinct integral solutions to (1)

\section{Properties:}


R.Umamaheswari and A.Kavitha

1. $x(A+1,1)+y(A+1,1)+8 t_{4, A}-8 t_{3, A}-2=0$

2. $y(B, B+1)+p(B, B+1)+4 t_{3, A}-2 t_{4, A}=0$

3. $y(B, B+1)+p(B, B+1)+4 t_{3, A}-2\left(t_{4, A}\right)^{2}+6 t_{4, A}=0$

4. $w(A, 1)+9 p(A, 1)-2 C P_{A, 6}-2 t_{20, A}-G_{A O}-27=0$

\subsection{Pattern 3}

(3) can be written as

$$
\mathrm{u}^{2}+3 v^{2}=p^{2} * 1
$$

Write 1 as,

$$
1=\frac{(1+i \sqrt{3})(1-i \sqrt{3})}{4}
$$

Using (7) and (11) in (10) and applying the method of factorization, define

$$
(u+i \sqrt{3})=(a+i \sqrt{3} b)^{2} \frac{(1+i \sqrt{3})}{2}
$$

Equating the real and imaginary part, we have

$$
\begin{aligned}
& u=u(\mathrm{a}, \mathrm{b})=\frac{1}{2}\left(a^{2}-3 b^{2}-6 a b\right) \\
& v=v(\mathrm{a}, \mathrm{b})=\frac{1}{2}\left(a^{2}-3 b^{2}+2 a b\right)
\end{aligned}
$$

As our interest is to find integer solution so we replace a by $2 \mathrm{~A}$ and b by $2 \mathrm{~B}$ we get,

$$
\begin{aligned}
& u=u(\mathrm{~A}, \mathrm{~B})=2 A^{2}-6 B^{2}-12 A B \\
& v=v(\mathrm{~A}, \mathrm{~B})=2 A^{2}-6 B^{2}+4 A B
\end{aligned}
$$

Using (12) in (2) the corresponding non-zero distinct integral solutions of (1) are given by

$$
\begin{aligned}
& x=x(A, B)=4 A^{2}-12 B^{2}-8 A B \\
& y=y(A, B)=-16 A B \\
& z=z(A, B)=4 A^{4}+32 A^{3}+24 A^{2} B^{2}-96 A B^{3}+36 B^{4}+1 \\
& w=w(A, B)=4 A^{4}+32 A^{3} B+24 A^{2} B^{2}-96 A B^{3}+36 B^{4}-1 \\
& p=p(A, B)=A^{2}+3 B^{2}
\end{aligned}
$$

\section{Properties:}

1. $p\left(A^{2}, A\right)-y\left(A^{2}, A\right)+16 C P_{A, 6}-\left(t_{4, A}\right)^{2}-3 t_{4, A}=0$

2. $w(1, B)+z(1, B)-8\left(t_{4, A}\right)^{2}-32 S O_{A}+320 t_{4, A}-208 t_{3, A}-72=0$

3. $x(A, A+1)+y(A, A+1)+64 t_{3, A}+16 p r_{A}-16 t_{4, A}+12=0$

\subsection{Pattern 4}


Integer Solution of the Homogeneous Bi-Quadratic Diophantine Equation with Five Unknowns

Write 1 as, $\quad 1=\frac{(1+i 4 \sqrt{3})(1-i 4 \sqrt{3})}{7^{2}}$

Proceeding as in Pattern: 3 the non-zero distinct integral solutions to (1) are $x=x(\mathrm{~A}, \mathrm{~B})=35 A^{2}-105 B^{2}-154 A B$

$y=y(\mathrm{~A}, \mathrm{~B})=-21 A^{2}+63 B^{2}-182 A B$

$z=z(\mathrm{~A}, \mathrm{~B})=196 \mathrm{~A}^{4}-3528 A^{2} B^{2}-4606 A^{3} B+13818 A B^{3}+1764 B^{4}+1$

$w=w(\mathrm{~A}, \mathrm{~B})=196 \mathrm{~A}^{4}-3528 A^{2} B^{2}-4606 A^{3} B+13818 A B^{3}+1764 B^{4}-1$

$p=p(\mathrm{~A}, \mathrm{~B})=147 B^{2}+49 A^{2}$

\section{Properties:}

1. $p\left(2^{\mathrm{n}}, 1\right)=147 J_{2 A}+196$

2. $x(\mathrm{~A}, \mathrm{~A})+y(\mathrm{~A}, \mathrm{~A})+p(\mathrm{~A}, \mathrm{~A})+168 t_{4, A}=0$

3. $x\left(\mathrm{~A}^{2}, \mathrm{~A}\right)+p\left(\mathrm{~A}^{2}, \mathrm{~A}\right)-84\left(t_{4, A}\right)-42 t_{4, A}-154 C P_{A, 6}$

\subsection{Pattern 5}

Write equation (3) as

$p^{2}-3 v^{2}=u^{2} * 1$

Let $u=a^{2}-3 b^{2}$

Write 1 as,

$$
1=(2+\sqrt{3})(2-\sqrt{3})
$$

Using (14) and (15) in (13) and applying the method of factorization, define $(p+\sqrt{3} v)=(a+\sqrt{3} b)^{2}(2+\sqrt{3})$

Equating the positive and negative parts of the above equations, we have

$$
\begin{aligned}
& p=p(A, B)=2 \mathrm{~A}^{2}+6 \mathrm{~B}^{2}+6 A B \\
& v=v(A, B)=4 A B+\mathrm{A}^{2}+3 \mathrm{~B}^{2}
\end{aligned}
$$

Substituting(13) and (17) in (2) we get

$$
\begin{aligned}
& x=x(\mathrm{~A}, \mathrm{~B})=21 A^{2}+4 A B \\
& y=y(\mathrm{~A}, \mathrm{~B})=-3 B^{2}+4 A B \\
& z=z(\mathrm{~A}, \mathrm{~B})=A^{4}+4 A^{3} B-12 A^{3} B-9 B^{4}+1 \\
& w=w(\mathrm{~A}, \mathrm{~B})=A^{4}+4 A^{3} B-12 A^{3} B-9 B^{4}-1
\end{aligned}
$$

Thus, (16) and (18) represent the non-zero distinct integral solutions to (1)

\section{Properties:}

1. $x\left(\mathrm{~A}^{2}, \mathrm{~A}\right)+y\left(\mathrm{~A}^{2}, \mathrm{~A}\right)-2\left(t_{4, A}\right)^{2}-S O_{A}-3 O H_{A}-4 C P_{A, 6}+3 t_{4, A}=0$

2. $z(\mathrm{~A}, 1)+w(\mathrm{~A}, 1)+16 C P_{A, 6}-2\left(t_{4, A}\right)^{2}+18=0$ 
R.Umamaheswari and A.Kavitha

3. $p(\mathrm{~A}+1, \mathrm{~A})+x(\mathrm{~A}+1, \mathrm{~A})-2 t_{4, A}-36 t_{3, A}-4=0$

Note:

Write 1 as

$$
1=(7+4 \sqrt{3})(7-4 \sqrt{3})
$$

Proceeding as in the Pattern 5, the non-zero distinct integral solutions to (1) are

$$
\begin{aligned}
& x=x(\mathrm{~A}, \mathrm{~B})=2 A^{2}+4 A B \\
& y=y(\mathrm{~A}, \mathrm{~B})=-3 B^{2}+4 A B \\
& z=z(\mathrm{~A}, \mathrm{~B})=A^{4}+4 A^{3} B-12 A^{3} B+1 \\
& w=w(\mathrm{~A}, \mathrm{~B})=A^{4}+4 A^{3} B-12 A^{3} B-1 \\
& p=p(\mathrm{~A}, \mathrm{~B})=49 A^{2}+147 B^{2}
\end{aligned}
$$

\section{Properties:}

$$
\begin{aligned}
& \text { 1.w }(1, \mathrm{~B})+p(1, \mathrm{~B})-36\left(t_{4, A}\right)^{2}-6 C P_{A, 7}-35 C P_{A, 6}-t_{44, A}-10=0(\bmod 3) \\
& \text { 2.p(A, A })+y(\mathrm{~A}, \mathrm{~A})-20 t_{4, A}=0 \\
& \text { 3.x }(\mathrm{A}, 1)+y(\mathrm{~A}, 1)-4 t_{3, A}+2 \mathrm{Pr}_{A}+6=0
\end{aligned}
$$

\section{Conclusion}

In this paper, we illustrated different methods of obtaining integer solutions to the biquadratic equation with five unknowns $(x-y)\left(x^{3}-y^{3}\right)=\left(z^{2}-w^{2}\right) p^{2}$. As bi-quadratic equations are rich in variety, one may consider the other forms of equations and search for their corresponding integer solutions.

\section{REFERENCES}

1. R.D.Carmichael, The theory of numbers and Diophantine Analysis, New York, Dover, (1959).

2. L.E.Dickson, History of theory numbers, Vol.2, Diophantine Analysis, New York, Dover, (2005).

3. M.A.Gopalan, Manjusomanath and N.vanitha, Parametric integral solutions of $\mathrm{x}^{2}+\mathrm{y}^{3}=\mathrm{z}^{4}$ Acta Ciencia Indica, XXX111H (4), (2007) 1261-1265.

4. M.A.Gopalan and V.Pandiselvi, on the Ternary biquadratic Diophantine equation $\mathrm{x}^{2}+k \mathrm{y}^{3}=\mathrm{z}^{4}$, Pacific Asian Journal of Mathematics, 2(1-2) (2008) 57-62.

5. M.A.Gopalan, Manjusomanath and N.Vanitha, Integral solution of $\mathrm{x}^{2}+x y+\mathrm{y}^{2}=\left(\mathrm{K}^{2}+3\right)^{n} z^{4}$, Pure and applied Mathematical sciences, LXIX(1-2) (2009) $149-152$.

6. M.A.Gopalan, V.Pandiselvi, on the solutions of the equation biquadratic $\left(\mathrm{x}^{2}-y^{2}\right)^{2}=\left(\mathrm{z}^{2}-1\right)^{2}+w^{4}$, International conference on Mathematical methods and computation at Jamal Mohamed College, (2009) 24-25. 
Integer Solution of the Homogeneous Bi-Quadratic Diophantine Equation with Five Unknowns

7. M.A.Gopalan and P.Sanmuganandham, on the Biquadratic equation $\left(\mathrm{x}^{4}+y^{4}\right)+(\mathrm{x}+y) z^{3}=2\left(\mathrm{k}^{2}+3\right)^{2 n} w^{4}$, Bessel J. Math., 2(2) (2012) 93-100.

8. M.A.Gopalan, S.Vidhyalakshmi and K.Lakshmi, on the Biquadratic equation with four unknowns $x^{2}+x y+y^{2}=\left(z^{2}+z w+w^{2}\right)^{2}$ IJPANS, 5(1) (2012) 73-77.

9. M.A.Gopalan, K.Meena, S.Vidhyalaksmi, S.AarthyThangam, On the biquadratic equation with four unknowns $\mathrm{x}^{2}+y^{2}=39 z w^{2}$, IJOER, 2(1) (2014) 57-60.

10. M.A.Gopalan, S.Vidhyalaksmi, A.Kavitha and E.Premalatha, on the homogeneous bi-quadratic equation with five unknowns $\mathrm{x}^{4}-y^{4}=5\left(\mathrm{z}^{2}-w^{3}\right) R^{2}$ International Archive of Applied Sciences and Technology, 4(3) (2013) 37-44.

11. M.A.Gopalan, A.Kavitha and G.Thamaraiselvi observation on the bi-quadratic equation with five unknowns $(\mathrm{x}-\mathrm{y})\left(\mathrm{x}^{3}+y^{3}\right)=\left(2 k^{2}+2 k+2\right)\left(\mathrm{X}^{2}-Y^{2}\right) w^{2}$ Multidisciplinary Research and Development, 2(6) (2015) 333-337.

12. S.Vidhyalaksmi, A.Kavitha and M.A.Gopalan, on the integral points bi-quadratic equation with four unknowns $(\mathrm{x}-\mathrm{y})\left(\mathrm{x}^{2}+y^{2}\right) z=12 z w^{3}$ Scholars Journal of physics Mathematics and statistics, 1(2) (2014) 45-47. 